\title{
Preparing Students For Class: A Hybrid Enhancement To Language Learning
}

John W. Schwieter, Wilfrid Laurier University, Canada

\begin{abstract}
Ensuring that students spend time preparing for class has always been one of the challenges of teaching. Indeed, when students are given an assignment that they are required to do before coming to the next lecture-whether it be written exercises or just studying-one wonders how often they are actually doing it. There are many ways in which teachers can evaluate whether or not students are prepared for class (i.e., have done "their reading"). Some of these methods to promote more out-of-class studying have included collecting written homework, giving quizzes, and even extra credit. This paper discusses the role of technology in the classroom as an alternative means to ensure student preparation for class lectures. In particular, this paper reports on a particular hybrid Spanish language program which was implemented at a large university in the United States. In this program, in addition to spending the traditional class time with an instructor, students are engaged in on-line, out-of-class activities related to the immediate subsequent class lecture. Solidly grounded in contemporary theories of second language acquisition, this program has shown that students are not only more prepared for class, but that the instructor is able to devote more class time to practice meaningful communicative activities in Spanish with the students. This paper ends with a section reporting opinions and testimonials from instructors and students of the Spanish hybrid language program.
\end{abstract}

\section{INTRODUCTION}

$\mathrm{n}$ a perfect world all college students would devote more than enough time to prepare themselves for their upcoming classes before meeting with the professor. Unfortunately, we must face the fact that this is not the norm in college courses. Many times students attend the class lectures and wait to study and review the information until just before the exam - cramming all of the material in so quickly that they are likely to forget most of it within a few days. This means that those students who fall into the trap of procrastination haven't been keeping up and in turn, have limited themselves in the extent to which they can engage themselves in class lectures. This can take away from class time that should be devoted to applying what was read outside of lecture. Indeed, making sure that students get the most out of the time with their instructor and peers is one of the many challenges that teachers constantly face.

Student unpreparedness is not limited to certain disciplines. In the foreign language classroom, for example, students are many times expected to be working on written, listening (lab), and grammar activities, vocabulary memorization, etc. outside of class. This is mainly due to the fact that although there are many theories that explain how a second language is acquired, the one thing that is most certainly shared is that language is best learned when learners are engaged in meaningful interaction in the target language. Ultimately, instructors of Spanish, for example, would like to be able to devote the majority of class time to activities that promote meaningful interaction in Spanish. However, as mentioned above, if students have failed to study the information before coming to class, the teacher may find him/herself engaged in extensive grammar explanations - (those in which students are performing mechanical (grammatical) drills and little interaction in the target language is maintained). How can teachers ensure that students are preparing themselves for class without compromising the theories of second language acquisition and their implications on language learning in the classroom? 
In this paper, I discuss a particular hybrid Spanish language program which was implemented at a large university in the United States. Firstly, I present an overview of the hybrid program and its role in the foreign language classroom. Secondly, I explore the theoretical background of the hybrid program and discuss how it facilitates the implementation of these theories into the classroom. I then proceed to highlight some feedback, both positive and negative, from instructors and students who have participated in the hybrid program. From these comments, I provide considerations that instructors and administrators must consider when contemplating the implementation of a hybrid program.

\section{THE HYBRID PROGRAM}

\section{Overview Of The Program}

In several large universities across the United States, many foreign language programs have implemented a hybrid element to their curricula. Essentially, in such a program, students complete activities on-line (at home or in a language lab) that do not require interaction. This type of program allows for language instructors to devote more time in class that will facilitate conversation in the target language. Implementing a hybrid program, thus, can be an effective way of establishing a crucial link between pedagogy in theory and pedagogy in practice.

In one particular large university in the United States, a hybrid program was implemented in the Spanish Basic Language Program, which consists of three sequential Spanish language courses: two levels of elementary Spanish and one level of intermediate Spanish. Before the transition, students had traditionally met with their instructor four days per week for lecture and one day per week for laboratory exercises.

It was estimated that in the traditional Spanish language program, instructors were spending $20 \%$ of their time on laboratory exercises and approximately $50 \%$ on conversation/application activities, and $30 \%$ on grammar explanations. Despite the fact that only about half of the typical instructors' time was spent on conversation practice, the traditional program considered itself as having a "communicative approach." In 2005, the program was restructured to include a hybrid portion that would help deliver out-of-class grammar and laboratory exercises. Under this practice, instructors could reduce their lecture time to three days per week and spend the majority of class time interacting in Spanish.

In the hybrid program at this particular university, $20 \%$ of the students' final grade is based on their completion of the audio/written activities presented to them online. Most of these activities were taken from the traditional workbook and laboratory manual (which typically contains most of the solutions to the answers at the end of the book). In addition, and probably more importantly, the administrative features of the program used to deliver the online activities allow for the instructor to regulate the deadlines of the activities. With regard to the preparedness of students, the hybrid program sets the deadline of these activities so that students must read and study the information and complete practice activities related to the content before attending class with the instructor. For example, if the instructor is teaching indirect object pronouns in class in Tuesday's 12:00PM Elementary Spanish I class, the students will have read and studied the pages in the textbook and completed activities on indirect object pronouns sometime before 8AM that day (i.e., activities are set to deactivate at that time).

\section{Goals Of The Program}

The primary object of the hybrid program is theoretical in nature. Essentially, the program facilitates the implication of teaching practices that assist in Spanish language learning, namely, meaningful interaction in the target language. The fact of the matter is that when learners study a language that is not the dominant language of the speech community, they will rarely have any conversations in the minority language outside of class time. It is the instructor's responsibility to ensure that the valuable class time, then, is devoted to the meaningful interaction that has been proven to be essential in second language acquisition. The hybrid program puts the students in charge of learning the grammar and completing laboratory activities in a systematic manner so that they may be better prepared to interact in the target language with other students during lectures with the instructor. 
Traditionally, students completed activities in a paper-based manual of laboratory and written exercises. The careful instructor would spend hours correcting the students' answers (not all of the workbook's answers are in the back of the book). Two additional goals of the hybrid program can be identified regarding the replacement of the paper-based manual. First of all, the program seeks to alleviate the time that teachers spend correcting laboratory and written exercises. This is achieved because the online activities are graded and recorded in the online grade book. In addition to being able to monitor their progress in the course, students are also given feedback for their mistakes. For example, if a student chooses "nos" (incorrect) instead of "le" (correct) for the question, "A María doy el libro de matemáticas," the computer would mark this answer wrong and explain to the student something to the effect of, "This answer is incorrect. Remember that the indirect object pronoun is le when it refers to him or her."

The second goal relating to the paper-based manual is that the hybrid program pushes students to be more independent of relying on the answers provided at the back of the book (or even just copying the without checking). When one particular class at the university reported in this paper was asked how many of the students used to simply copy the answers out of the back of their traditional paper-based workbooks, $68 \%$ of them admitted to doing so regularly. Some instructors stressed the importance of using these answers only as a guide and others didn't care if the students copied them or not. Nonetheless, this is not an issue in the hybrid program due to the fact that students only purchase a publisher access code which gives them the right to access the questions via the hybrid program. These questions are not presented with the answers.

Finally, another goal of the hybrid program is to expose students to structured input activities which, according to VanPattens' $(1996,2000)$ model of input processing, are crucial in second language acquisition. More information regarding the types of activities used and the theoretical framework on which they are based will be discussed in the next sections.

\section{THEORETICAL BACKGROUND OF THE HYBRID PROGRAM}

The hybrid program is based on the theoretical framework of VanPatten's $(1996,2000)$ input processing model. Input processing has laid the groundwork for processing instruction, the pedagogical considerations and practices drawn from input processing. The next two sections discuss input processing and processing instruction and their role in language learning.

\section{Input Processing}

Research in second language acquisition has pointed out that one of the most important elements in language learning is the role of comprehensible input (see Gass, 1997 for a review). Indeed, without input of some sort in the target language, it is very unlikely that the learner will acquire that language. Needless to say, not all input is processed by language learners. There is a marked difference between what learners will hear and what they will get. The former is termed input and the latter is defined as intake. Intake is essentially what is taken from the input and stored in the working memory for further processing. One model that explains how language learners derive intake from input is VanPatten's $(1996,2000)$ model of input processing. Input processing is based upon a set of psycholinguistic processing strategies that learners use during the conversion of input to intake. The four major processing problems that have been put forth by VanPatten $(1996,2002,2004)$ are listed below with accompanying examples in Spanish language learning:

1. Learners process input for meaning before they process it for form. Content words are processed before anything else.

Example: Ricardo es la persona que está encargada de hacer la reunión. Content words such as Ricardo, persona, and reunión that carry more meaning will be most likely to be processed before the functional words such as que and la.

2. Learners prefer processing lexical items to grammatical items for the same semantic information.

Example: Juan organizó la fiesta anoche. In this example, the $o$ and anoche both provide information referring to the past tense. A learner is more likely to process anoche than the morpheme $o$. 
3. Learners process a default strategy that assigns the role of agent (or subject) to the first noun they encounter in a sentence/utterance. This may be overridden by lexical semantics and event probabilities.

Example: Isabel le gusta a Juan. In this example, Juan likes Isabel. However, because Isabel is the first noun that a learner sees or hears, it may be interpreted as Isabel likes Juan.

4. Learners process elements in the first part of a sentence/utterance first; elements in the last part of a sentence/utterance next; and elements in the middle part of a sentence/utterance last.

Example: Es importante que los estudiantes escuchen durante clase. In this example, the use of the subjunctive mood (escuchen) is located in the middle of the sentence. The part of the sentence that is most likely to be processed (or processed first) is the first and then last parts of the sentence. The subjunctive is a difficult construction for learners to acquire because it is almost always found in the middle parts of sentences/utterances in Spanish.

\section{Processing Instruction}

VanPatten (1996) has claimed that processing instruction is a psycholinguistically motivated approach to focus on form whose main aim is to teach grammar without sacrificing either communication or learning-centered activities. Essentially, processing instruction includes pedagogical considerations that have been based on theories of input processing.

In their seminal article, VanPatten and Cadierno (1993) introduced processing instruction, a teaching technique that they hypothesized would help learners make more gains in their interlanguage (i.e., developing systems) because structured input activities force them to process the input differently. Essentially, this study sought to compare processing instruction to traditional instruction. VanPatten and Cadierno suggested that processing instruction "involves explanation and practice/experience processing input data, taking learner strategies in input processing as the starting point for determining what explicit instruction should look like" (p. 225). Traditional instruction, on the other hand, only provides explicit information followed by output practice which is usually low in communicative value.

VanPatten and Cadierno (1993) examined non-SVO order (a grammatical possibility common in Spanish). Eighty second-year university-level Spanish language learners were randomly assigned to three groups: 1) no instruction (i.e., control group; $\mathrm{N}=27)$; 2) processing instruction ( $\mathrm{N}=27)$; and 3) traditional instruction $(\mathrm{N}=26)$. A pretest and three posttests were conducted that consisted of both interpretation and written production tasks. In addition, on each of these four data collection days, a distracter task in which participants answered unrelated questions to the experiment.

VanPatten and Cadierno's (1993) results showed significant gains in both comprehension and production for the processing instruction group, while the traditional instruction group only exhibited gains in production. As expected, the control group showed no significant increases. They conclude that traditional instruction and practice where meaning is not kept in focus do not enhance learners' ability to interpret input.

Because all of the participants in VanPatten and Cadierno (1993) received explicit information, VanPatten and Oikkenon (1996) explored whether or not the explicit information given to the learners receiving processing instruction is what was responsible for the benefits of the processing instruction group found in VanPatten and Cadierno. Fifty-five students studying forth-year Spanish in grade 12 were placed in three groups: 1) processing instruction (PI); 2) explicit only (EO); and 3) structured input only (SI). If explicit information is what plays a role in increased interpretation and/or production, there should not be as many gains in the group which has did not get explicit information (SI). The instrumentation was the same as VanPatten and Cadierno in that there were two tasks: an interpretation and a written production task. A pretest and a posttest consisting of the two tasks were given to all groups. The results support VanPatten and Cadierno. From pretest to posttest, as far as the production task is concerned, the processing instruction group preformed the best, followed by the structured input group, and finally the explicit only group (PI>SI>EO). As far as the interpretation task, PI outperformed EO and SI outperformed EO (PI>EO; SI $>$ EO). VanPatten and Oikkenon concluded that both studies' results suggest that the benefits of processing instruction were due to structured input activities and not to the explicit information. 
Processing instruction shows that the generalization "practice does not make perfect" (Lightbown, 1985, 2000 ) is true when "practice" consists of mechanical drills where meaning is not kept in focus. The two studies mentioned above suggest that processing instruction, in which learners' processing strategies are altered to make more form-meaning connections via structured input activities, promotes the process of input to intake. Activities found in traditional teaching methodology (e.g., mechanical/grammar drills) were not shown to help learners at least in terms of interpretation tasks because they do not seem to keep meaning in focus (VanPatten \& Cadierno, 1993).

\section{IMPLICATIONS IN THE CLASSROOM AND IN THE HYBRID ACTIVITIES}

The activities that form part of the online exercises in the present hybrid program are structured input activities. These activities promote the process of input to intake (i.e., actually processing what is provided) and are presented in a way in which they help to reverse the "bad" processing strategies that second language learners bring with them. The following is an example of structured input activities that students complete in the hybrid program.

1. _ piensa en lo positivo del futuro.

always thinks about positive

(aspects) of the future].

a. Una persona pesimista [a pessimistic person]

b. Una persona optimista [an optimistic person]

c. Una persona desorganizada [an unorganized person]

Another important element briefly mentioned above regarding the activities that students complete in the hybrid program is that they are regulated by a time management system. In the hybrid program, students are given a calendar of dates on which certain activities must be completed. The deadline for these activities has been set so that students must complete the appropriate day's lecture topic by 8AM that day (i.e., students must always study the material and complete activities related to the material before they attend class with the instructor). This timing feature has been established not only to ensure that students are more prepared for class time, but to also give the instructors more time to practice meaningful, communicative activities with the students.

\section{FEEDBACK FROM INSTRUCTORS OF THE HYBRID PROGRAM}

At the present, this program was beginning its forth year. Below I present some positive feedback that was elicited from instructors and students from the Spanish hybrid program during its third year.

\section{Positive Feedback}

1. I like that the instructor doesn't have to grade the entire workbook and lab manuals. This takes much time and many times students don't even look at our corrections we make. I also like that students can access these activities from any computer with an internet connection and that they receive automatic feedback and their assigned grade is recorded directly to a grade book.

2. I actually get the feelings that my students seem to be more prepared when they come to class after having done the hybrid, online activities.

3. I pay attention to environmental issues and I like that the hybrid program reduces the amount of paper that is used, unlike traditional programs with paper workbooks and lab manuals.

4. The hybrid program has allowed us to keep students' grades up-to-date and accessible to them. This reduces the amount of times that you get asked the "what's my grade?" question.

5. The hybrid program keeps students on their toes because there is this pressure from them to do well on the online activities because all the points count. Also, they know that the machine is less "forgiving" than a human (and it eliminates human error!).

6. Nowadays with students spending so much time on the Internet, it seems more "natural" for them to do homework on the internet for the hybrid program. They probably would rather do this than book work anyway.

7. Teachers have more time to prepare their courses outside of class because the hybrid program has reduced class time - and students like this too! 
8. The hybrid program is an excellent way to be on the cutting edge of new technology in the classroom. I think that many students look at this type of program as "cool." This motivates them and is an innovative way in which they can connect with the Hispanic world.

9. I think the program gives students the freedom to pace themselves as they feel most comfortable. This allows them to establish a routine that allows them to review and study on their own outside of class.

10. I feel the hybrid program satisfies many important components that are most beneficial to the student. The hybrid allows the student to have access to it from any where [dorms, wireless connections around campus, and at home] making it more user-friendly for the student. The hybrid also allows the student to be more focus on their own work when they are working online. For the student who tends to be shy, It gives him/her the opportunity to show skills that in class the instructor might not get to see. And for the Professor, the hybrid offers more supervision over the activities the students do.

11. I do think that technology is a great tool that can make the professor's life so much easier, can bring excitement to the class, and can help students perceive the target language and culture through more than one sense at a time. By having a hybrid course, students can take advantage of the internet and the computer and use those tools to study and review mechanical functions of the language -such as grammarwhich can save time for apply the concepts in the classroom and actually produce language. Likewise, technology can help the professor exemplify and explain vocabulary words without using translation, but pictures, movement, and sound. It can also be used to present the students different accents by the use of videos from several countries, so that students get accustomed to voices and speech rates other than their professor.

Although the Spanish hybrid program is well-received by its instructors, some were eager to bring forth some negative aspects to this technology-enhanced element. Below I present some negative feedback that has been elicited from instructors from the Spanish hybrid program.

\section{Negative Feedback}

1. One thing that seems to be a negative to the hybrid program - something very important to me-is that it reduces the amount of "contact" that instructors have with students in the classroom. At the end of the day, riding a bike is learned by getting on a bike, and a language is the same. It is not the same to hear audio slips and other audio material than to converse with another human. So, one negative is that students have less interaction in class than in the non-hybrid program setting.

2. I feel that one of the down sides to the hybrid program is that students complain that there are too many activities online. Also, some students even comment that they would rather be in class than have an element similar to an "online course." This should change.

3. Some students are at a slight disadvantage because they don't have a computer at home or in their dorm room. But, on the other hand, there are computers all over campus with the necessary equipment [internet access and headphones] to allow students to complete their activities.

4. The hybrid program may contribute to more pressure and anxiety among students to do well on the countless activities they have to complete.

5. I found that at times it was frustrating to have to deal server downtime or e-mails from students saying that either an activity's audio link was not working.

6. The hybrid program suggests that students are responsible and hardworking enough to manage their time outside of class and to not have their instructor making sure they are doing what they are supposed to do. Unfortunately, some students - especially the younger ones - haven't matured quite yet...

7. The activities from the book and the ones on the hybrid program seem to be similar and too repetitive.

8. Having a Master's Degree in Interactive Communication and New Technologies and in Spanish Literature and Linguistics makes feel very comfortable when teaching a hybrid course. When I received my Master's I knew I wanted to combine the technology skills I got and my teaching experience, I wanted to teach using technology as a tool. I do not see online courses beneficial because the students do not have contact with the professor and in my opinion a computer can not replace a professor. 


\section{FEEDBACK FROM STUDENTS OF THE HYBRID PROGRAM}

\section{Positive Feedback}

1. [I liked most] being in class three times a week, it gave you a break from pounding new material in my head everyday.

2. Because we met less frequently than previous Spanish classes, the extra days that we didn't have class, we were able to practice the material that the teacher will teach us in the next class.

3. The hybrid program helped me pace myself and keep up with my work.

4. The online exercises provided additional lessons and examples and provided repetition.

5. It forced us to do homework, which is something we all know most wouldn't do if we didn't have to.

6. By doing the activities online, I was able to actually go to class and have the material reiterate what I had already studied.

7. It allowed me to really work with the material by presenting it in new contexts.

\section{Negative Feedback}

1. I didn't like how many of the activities included popular culture. I felt that sometimes the questions were asking us more about what we knew about famous people than the Spanish language.

2. Many of the audio activities included native speakers who talked too fast.

3. There were sometimes technical difficulties that wouldn't allow us to hear some of the audio links.

4. I feel that the trade-off from not going to class four or five days per week to having to do countless hours of online work with only three days of lecture is not a fare trade. It seems like the hybrid element takes a lot of time out of our "off" days.

5. I just don't like anything about the hybrid program; it just doesn't make sense that we are forced to learn material before having the instructor tell us about the material...isn't that his job?

6. Many of the questions were full of subjective information like, what's the color of Nicole Kidman's hair? We all know that her hair has been a different shade of red, brown, or black in the last decade.

7. On-line activities include a self-grading part that is too rigid to allow for small things like a capital letter.

\section{THINGS TO KEEP IN MIND WHEN CONSIDERING HYBRID PROGRAM IMPLEMENTATION}

Leeser and Gramling (2007) have noted that although a hybrid program of language instruction has yielded excellent results and is meeting their curricular and instructional needs for the Spanish program at their institution, they warn that this type of program may not be similarly beneficial to other institutions wishing to redesign the structure of their program. Indeed, they provide a highly useful list of questions that are imperative to answer when an institution is considering transitioning from a traditional to hybrid program. For instance, they pose questions that prompt administrators to think about issues such as whether or not their institution has a course management system that provides technology support for faculty and students. This is certainly an important consideration because although technology is a wonderful tool that opens new venues of learning, it is known to occasionally "crash" or not respond/execute as humans wish. Having an excellent team of technology experts (i.e., instructional technology services) is critical when implementing a hybrid program that requires constant collaboration, support, and feedback from multiple parties. Essentially, there are three main agents involved in the hybrid program. First, and foremost, are the students who are participating and learning in this technology-assisted environment. The other two groups involved which form the administrative aspect of the hybrid program are the instructors and technology experts. It is obvious that constant communication must be maintained between the instructors and the technology expertsespecially in the initial stages of implementation. Furthermore, there must be collective communication between the students and the instructors. If there are problems with activities, students will alert their instructors who may need to consult the technology experts. It can be seen, thus, that one of the most critical elements when considering implementing a hybrid language program, is an excellent team of technology experts who can provide instructors with assistance. 
Another key question that needs to be entertained before an institution should implement a hybrid program is student-focused in nature. Administrators must ask themselves what a hybrid program that provides students with web-based activities and assessments can offer the students in their program. It seems silly to mention the fact that considering the students in this hybrid program is a necessity but, essentially, what all this boils down to is providing the best outlet for language learning for students. Under this appropriate assumption, one must consider the types of technology-enhanced activities that most effectively facilitate student-center learning while, at the same time, allow for retention of the information.

\section{CONCLUSION}

In this paper, I have outlined a hybrid program of Spanish language learning that has been successfully implemented at a large university in the United States. Among the many things that this program accomplishes in the college foreign language classroom is that it pushes students to be better prepared for class time (i.e., it ensures that they are 'doing their homework'). While following theories of second language acquisition put forth by VanPatten's (1996, 2000) input processing framework, this hybrid program has shown to be an effective way of ensuring that class time can be devoted to contextualized, communicative activities in the target language while providing activities that attempt to break down the negative processing strategies that learners bring with them in second language acquisition. This paper also reported positive and negative feedback that has been provided by students and instructors of the hybrid program. Although these comments demonstrated an overall positive tone towards the hybrid program, many students identified a problem in the online activities, namely the fact that they made many references to pop culture. The last section of this paper presented a brief discussion of Leeser and Gramling's (2007) study which highlights key factors to consider when implementing a hybrid element into an existing curriculum. These recommendations are essential if the hybrid program is to achieve the desired results. In all, the present paper has presented an innovative and effective way of ensuring that students prepare themselves outside of class so that their classroom environment is optimal for second language acquisition.

\section{AUTHOR INFORMATION}

Dr. John W. Schwieter is an Assistant Professor of Spanish and Linguistics at Wilfrid Laurier University in Waterloo, Ontario. His research focuses on the cognitive processes involved in language production during second language acquisition. In his research, Dr. Schwieter has found evidence suggesting that the underlying mechanisms controlling the words in the bilingual mind change as language learners become more proficient in their second language. Dr. Schwieter was also part of a research group in which a hybrid Spanish language program was created and implemented at Florida State University in Tallahassee, Florida.

\section{REFERENCES}

1. Gass, S. (1997). Input, Interaction, and the Second Language Learner. Mahwah, NJ: Lawrence Erlbaum.

2. Leeser, M., \& Gramling, J. (2007, April). The best of both worlds: Planning and implementing hybrid language instruction. The Language Educator.

3. Lightbown, P. (1985). Great expectations: Second language acquisition research and classroom teaching. Applied Linguistics, 6, 173-189.

4. Lightbown, P. (2000). Classroom SLA research and second language teaching. Applied Linguistics, 21(4), 431-462.

5. VanPatten, B. (1996). Input processing and grammar instruction: Theory and research. Norwood, NJ: Ablex.

6. VanPatten, B. (2000). Processing instruction as form-meaning connections: Issues in theory and research. In J.F. Lee \& A. Valdman (Eds.), Form and Meaning in Language Teaching (pp. 43-68). Boston: Heinle and Heinle.

7. VanPatten, B. (2002). Processing instruction: an update. Language Learning, 52(4), 755-803.

8. VanPatten, B. (Ed.) (2004). Processing Instruction: Theory, Research, and Commentary. Mahwah, NJ: Lawrence Erlbaum Publishers. 
9. VanPatten, B. \& Cadierno, T. (1993). Explicit instruction and input processing. Studies in Second Language Acquisition, 15, 225-243.

10. VanPatten, B. \& Oikkenon, S. (1996). The causative variables in processing instruction: Explicit information versus structured input activities. Studies in Second Language Acquisition, 18, 495-510.

\section{NOTES}


NOTES 